\title{
Heteroatom Doped Multi-Layered Graphene Material for Hydrogen Storage Application
}

\author{
Arjunan Ariharan 1,2, Balasubramanian Viswanathan 1*, Vaiyapuri Nandhakumar ${ }^{2}$ \\ ${ }^{1}$ National Centre for Catalysis Research, Indian Institute of Technology Madras, Chennai, India \\ ${ }^{2}$ PG \& Research Department of Chemistry, AVVM Sri Pushpam College, Poondi, Bharathidasan University, \\ Trichy, India \\ Email: "bvnathan@iitm.ac.in
}

Received 26 January 2016; accepted 20 March 2016; published 23 March 2016

Copyright (C) 2016 by authors and Scientific Research Publishing Inc.

This work is licensed under the Creative Commons Attribution International License (CC BY).

http://creativecommons.org/licenses/by/4.0/

(c) (i) Open Access

\section{Abstract}

A variety of distinctive techniques have been developed to produce graphene sheets and their functionalized subsidiaries or composites. The production of graphene sheets by oxidative exfoliation of graphite can be a suitable route for the preparation of high volumes of graphene derivatives. P-substituted graphene material is developed for its application in hydrogen sorption in room temperature. Phosphorous doped graphene material with multi-layers of graphene shows a nearly $\sim 2.2 \mathrm{wt} \%$ hydrogen sorption capacity at $298 \mathrm{~K}$ and $100 \mathrm{bar}$. This value is higher than that for reduced graphene oxide (RGO without phosphorous).

\section{Keywords}

Hydrogen Storage, Carbon Materials, Graphene Materials, Heteroatom Doped Graphene, Phosphorous Doped Graphene, Hydrogen Storage Capacity

\section{Introduction}

The concept of ecologically acceptable, renewable and sustainable energy worries on the utilization of fossil fuels and their asset imperatives. This has led to the consideration of converting to hydrogen energy from renewable sources [1]-[4]. Hydrogen is an energy carrier not an energy source and therefore, energy must be converted before hydrogen can be employed as carrier. Be that as it may, one of the obstructions to the advancement of hydrogen fuel cell technology for versatile application is storage [5]. Compressed gas and liquid hydrogen storage systems are unrealistic to meet the forceful US Department of Energy (DOE) standards which focus for on-board hydrogen storage systems. Hydrogen transport as compressed gas in high pressure cylinders meets with the re-

"Corresponding author. 
striction of included cost. Safe and financially savvy storage are viewed as important for the predominant use of hydrogen in transport sector as well as in stationary and compact gadgets applications; with the transportation segment representing the most serious challenge [5] [6].

Solid state hydrogen storage where a host material is utilized as a hydrogen energy carrier, offers necessary volumetric energy densities. A variety of solid state hydrogen storage media have been analyzed in the previous decades in light of criteria like storage capacity, reversibility and cost [6]. Hydrogen storage in carbon materials has received consideration following the time when a storage capacity (however unimaginatively high) of around $67 \mathrm{wt} \%$ was reported by Chambers et al. [7]. In any case, till now, the required storage capacities according to DOE specifications for FY 2005 (4.5 wt\%), FY 2010 (6 wt\%) and 9 wt\% for FY 2015, have not been accomplished although considerable efforts have expanded in this direction. Carbon based materials have been considered for gas sorption, storage, and separation because of the abundance, robust pore structure, tunable porosity and surface area, light-weight, higher chemical and thermal stability, and facile synthesis in industrial scale. There is a lot of enthusiasm for graphene related materials for gas sorption, storage and separation yet an absence of far reaching survey on such a theme [8]-[11].

Since its introduction, graphene has seen critical advances in energy conversion and storage technologies because of its extraordinary properties derived from the two-dimensional layered structure of sp $^{2}$-hybridized carbon [12]. The properties and uses of graphene have been examined in the previous decade [12]-[17]. Graphene, a two-dimensional structure, a monolayer of carbon molecules stuffed into a honeycomb cross section, has attracted tremendous interest in a variety of fields [14] [18]-[22]. Basically graphene is folded, as opposed to planar, and every hydrogen atom bonded to carbon pulls it a small distance out of the plane, which is the mother of all graphitic forms including zero dimensional fullerenes, 1D carbon nanotubes (CNTs), and 3D graphite [23] [24]. Despite the fact that CNTs are formed through the rolling of graphene sheets, properties of these two materials are entirely diverse. Along these lines, graphene has attracted a lot of consideration in the last years in the field of energy storage materials [25]-[29]. The electronic and Raman spectra of CNTs and graphene contrast impressively. Electrical conductivity and mechanical strength also differ [30]. Reduction of GO (graphene oxide) for the preparation of graphene has attracted consideration for its enormous yield and minimal effort. The kind spatial and bonding arrangement of atoms through $\mathrm{sp}^{2}$ hybridization of all of the carbon-carbon bonds across the sheet has imparted fascinating properties for graphene [31] [32]. This prompts unprecedented electron mobility, and inherent material strength and thermal properties. Furthermore, graphene shows interesting properties, one of them being surface-area-to-volume proportion in a layered material [33] [34]. Imperatively, these properties of graphene are fundamentally diverse to those of the stacked three-dimensional form of carbon, graphite [35] [36]. Recently, heteroatoms like nitrogen, boron and phosphorous, introduced as dopants into the carbon materials, have been studied to increase the hydrogen storage capacity [37]-[47].

Doping of graphene with different heteroatoms that is the graphitic carbon atoms are substituted or covalently bonded by other atoms has been studied [48]-[53]. However the substitution of phosphorus in carbon materials has not been examined to the same extent. Especially pertinent for hydrogen capacity applications is the way that graphene can be presently delivered on a substantial and practical scale by either beat down (for example, exfoliation from mass) or bottom up (atom by atom development) strategies. Graphene has been considered as a potential candidate for hydrogen storage if doped with alkali and alkaline earth metal [54] [55]. Interestingly, recent experimental and theoretical studies in the energy related research fields showed that the doping of $\mathrm{N}$ and $\mathrm{B}$ atoms on carbon backbones could present a distortion in the nearby sites due to the variation in bond length and atomic size and thus interrupt the electro-neutrality of adjacent $C$ atoms and make charged destinations, which are positive for hydrogen adsorption and oxygen reduction [41] [43] [56]-[59]. On the other hand, phosphorous has the similar electron numeral as $\mathrm{N}$ and frequently shows similar chemical properties [44] [45]. As we might talk about in the following area this is pertinent since atomic hydrogen adsorption/desorption on graphene can be delicately controlled offering new systems for hydrogen storage. Herein, phosphorus doping into graphene sheets may enhance the chemical activity, and so may also improve hydrogen sorption characteristics [46]. However, modifying graphene materials with metal nanoparticles such as alkali and alkaline earth metals can develop the gravimetric storage capacity via the polarization-induced interaction between metal and hydrogen atoms [47]. Only limited reports are available for the synthesis of phosphorous substituted graphene and used as hydrogen storage material. However, no report has been found so far on whether or not the P-doping can improve the activity and the hydrogen storage capacity of graphene material. Furthermore, to the best of our knowledge, limited studies have been reported on the influence of the composition and morphology of the phosphorous- 
doped graphene has been reported.

In this study, the phosphorous substituted graphene was prepared through a simple and effective hydrothermal reaction under the assistance of $\mathrm{H}_{3} \mathrm{PO}_{4}$ as the phosphorous source. The phosphorous species could be tuned by controlling the hydrothermal reaction time [47]. Furthermore, other researchers have adopted phosphoric acid or phosphate as the phosphorus source for the synthesis of heteroatom (P) doped graphene or carbon nano materials. $\mathrm{H}_{3} \mathrm{PO}_{4}$ is a standout amongst the most cheap and regularly utilized activation and doping agents containing phosphorous [47] [48]. P-doped graphene could likewise be synthesized by other P-containing organics such as triphenyl phosphine or ammonium phosphate [49] [56] [60]-[65]. The structural, chemical, morphological and textural characteristics of the synthesized materials have been examined by powder X-ray diffraction patterns (PXRD), Fourier transform infrared spectroscopy (FT-IR), Confocal Raman spectroscopy, BET- $\mathrm{N}_{2}$ adsorption/desorption isotherms, high resolution scanning electron microscopy (HRSEM), high resolution Transmission electron microscopy (HRTEM), and X-ray photoelectron spectroscopy (XPS). The hydrogen storage capacity of the phosphorous substituted carbon material has been determined by high pressure volumetric analyzer (HPVA 100).

\section{Experimental Section}

\subsection{Materials}

Graphite powder (Extra pure), Sulfuric acid 98\% $\left(\mathrm{H}_{2} \mathrm{SO}_{4}\right)$, Sodium nitrate $99 \%\left(\mathrm{NaNO}_{3}\right)$, Potassium permanganate $99.5 \%\left(\mathrm{KMnO}_{4}\right)$, Hydrogen peroxide $30 \%$ purified $\left(\mathrm{H}_{2} \mathrm{O}_{2}\right)$, Phosphoric acid $88 \%\left(\mathrm{H}_{3} \mathrm{PO}_{4}\right)$ were purchased from Sigma Aldrich and used without further purification.

\subsection{Synthesis Method}

The schematic illustration of the preparation of phosphorous doped multilayered graphene material is shown in Figure 1. The typical synthesis procedure is as follows. Graphene Oxide (GO) was synthesized from graphite by a modified Hummers method [66]. Briefly, graphite powder (2.0 g) was taken in a beaker, added $50 \mathrm{~m}$ of concentrated sulfuric acid $\left(\mathrm{H}_{2} \mathrm{SO}_{4}\right)$ under vigorous agitation in an ice bath. Afterwards, sodium nitrate $(2.0 \mathrm{~g})$ and potassium permanganate $(6.0 \mathrm{~g})$ were slowly added in a sequence. Then, the mixture was transferred into a water bath and kept at $35^{\circ} \mathrm{C}$ for 2 hour. After that, $100 \mathrm{~mL}$ of distilled water was slowly added, causing a temperature rise to $98^{\circ} \mathrm{C}$. Later, $140 \mathrm{~mL}$ of $4 \% \mathrm{H}_{2} \mathrm{O}_{2}$ was dropped into the reaction system. Finally, the product was washed with distilled water three times. The acquired solid was dried in vacuum at $50^{\circ} \mathrm{C}$ for 48 hours.

The phosphorous doped multilayered graphene materials were synthesized as follows. Typically, $1.5 \mathrm{~g}$ of Graphite oxide was taken in a beaker. GO aqueous dispersion was diluted with $25 \mathrm{~mL}$ of distilled water, and

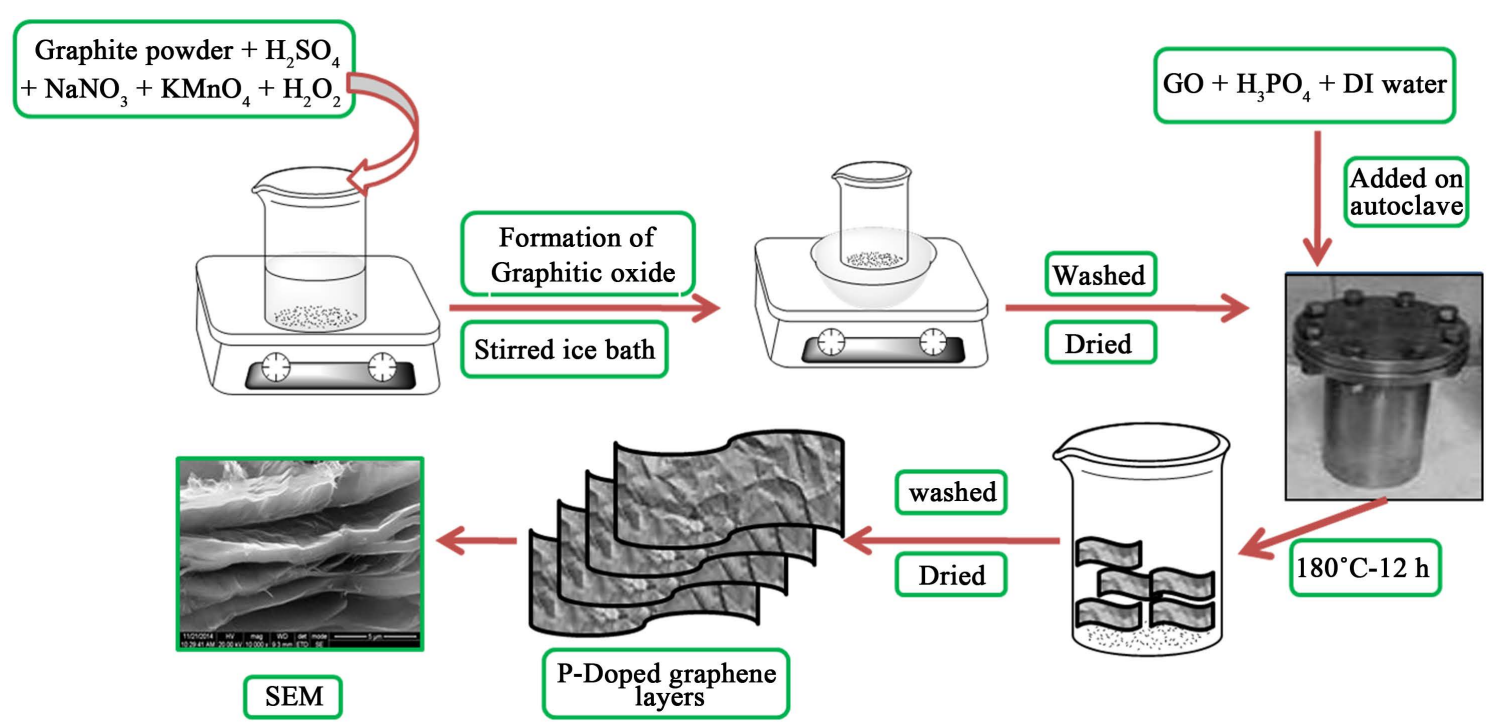

Figure 1. Schematic illustration of phosphorous doped multilayered graphene material. 
then $21 \mathrm{~mL}$ of $\mathrm{H}_{3} \mathrm{PO}_{4}$ solution was added into the GO dispersion under sonication for 2 hours. The hydrothermal reaction carried out and the solution was sealed in a $100 \mathrm{~mL}$ Teflon-lined autoclave and maintained at $180^{\circ} \mathrm{C}$ for 12 hours. Then, autoclave was naturally cooled to room temperature and the product was taken out. Then again the sample was annealed $500^{\circ} \mathrm{C}$ for 2 hours under inert atmosphere heating rate employed is $5^{\circ} \mathrm{C} / \mathrm{min}$. Then, the tubular furnace was allowed to cool automatically. The obtained products were filtered and washed with distilled water for three times. Finally, the collected sample was utilized for the characterization. For comparison, RGO was also prepared under the same experimental conditions but without adding the $\mathrm{H}_{3} \mathrm{PO}_{4}$ into the GO aqueous dispersion.

\subsection{Physical Characterization}

Wide angle Powder XRD pattern of the calcined carbon materials was recorded using a Rigaku Miniflex II diffractometer with $\mathrm{Cu} \mathrm{K} \alpha$ as the radiation source at a wavelength of $0.154 \mathrm{~nm}$ with $2 \theta$ angle ranging from $10^{\circ}$ to $80^{\circ}$ with a 0.02 step size. Fourier Transform Infrared Spectra (Perkin-Elmer FTIR spectrophotometer) were collected at room temperature by using the $\mathrm{KBr}$ pellet technique in the range of wave numbers $4000-400 \mathrm{~cm}^{-1}$. Fourier Transform Raman spectra were recorded by using the standard Bruker pulse FT-Raman spectrometer instrument. BET $\mathrm{N}_{2}$ adsorption and desorption isotherms were measured with surface area and porosity analyzer (Micromeritics Accelerated Surface Area and Porosimetry System (ASAP 2020)) for the determination of surface area and total pore volume at $77 \mathrm{~K}$. Prior to the adsorption measurements, the sample was degassed at $473 \mathrm{~K}$ for 6 h. FEI Quanta FEG 200-High Resolution Scanning Electron Microscope (HRSEM) was employed for obtaining the micrographs. JEOL JEM-2000 High Resolution Transmission Electron Microscopy (HRTEM) was employed for obtaining the micrographs. X-ray photoelectron spectroscopy (XPS) measurements were performed with an Omicron Nanotechnology spectrometer with hemispherical analyzer. The monochromatized $\mathrm{Mg}$ $\mathrm{K} \alpha \mathrm{X}$-source $(\mathrm{E}=1253.6 \mathrm{eV})$ was operated at $15 \mathrm{kV}$ and $20 \mathrm{~mA}$. For the narrow scans, the analyzer pass energy of $25 \mathrm{eV}$ was applied. The base pressure in the analysis chamber is $5 \times 10^{-10}$ Torr. The hydrogen adsorption isotherms were carried out on high pressure volumetric analyzer (HPVA-100) from micromeritics particulate systems. The HPVA product operating pressure ranges from high vacuum to 100 bar. The span of the sample temperature during analysis can be from cryogenic to $500^{\circ} \mathrm{C}$. Sample analysis data collection is fully automated to assure quality data and high reproducibility.

\subsection{Hydrogen Adsorption/Desorption Isotherm}

High Pressure Volumetric hydrogen adsorption measurements have been carried out using High pressure volumetric analyzer (HPVA 100). The high pressure adsorption analyzer consists of a cylindrical sample cell of known volume (2 cc and $10 \mathrm{cc}$ ). All possible care for the possible sources of leak was carefully taken and long blank run tests were carried out. Care has been taken to avoid the errors due to factors such as temperature instability, leaks and additional pressure and temperature effects caused by expanding the hydrogen to the sample cell. The measurements were carried out by utilizing the systematic procedure as follows: typically the mass of the carbon samples used for hydrogen sorption measurements is in the range of $500 \mathrm{mg}-1 \mathrm{~g}$. Earlier to measurement, the samples are degassed and heated at $200^{\circ} \mathrm{C}$ for approximately $8 \mathrm{~h}$ in vacuum. The whole system has been pressurized at the desired value by hydrogen and change in pressure was monitored. All the hydrogen adsorption measurements have been carried out at room temperature. The experiments have been repeated under the same conditions for reproducibility.

\section{Results and Discussion}

Figure 2 shows the X-ray diffraction patterns of the prepared materials. There are two broad peaks around $26.3^{\circ}$ and $43.6^{\circ}$ corresponding to 002 and 100 reflections respectively. The FT-IR studies were carried out for the identification of functional groups present. The peaks at 1118 and $673 \mathrm{~cm}^{-1}$ can be attributed to P-O and P-C stretching vibrations. This result reveals that phosphorous is doped in the prepared graphene material (see Figure 3). Raman spectrum (Figure 4) shows two broad peaks around $1323 \mathrm{~cm}^{-1}$ and $1575 \mathrm{~cm}^{-1}$ generally designated as $\mathrm{D}$ and $\mathrm{G}$ bands [67] because of that phosphorous doped multilayered graphene were similar to those of the reduced graphene oxide (RGO), indicating the graphitic nature of the carbon material prepared.

However, the (002) diffraction peak in the XRD pattern of P-doped multilayered graphene was sharper and of higher intensity than that of RGO, and the $\mathrm{I}_{\mathrm{D}} / \mathrm{I}_{\mathrm{G}}$ ratio in the Raman spectrum of the P-doped multilayered gra- 


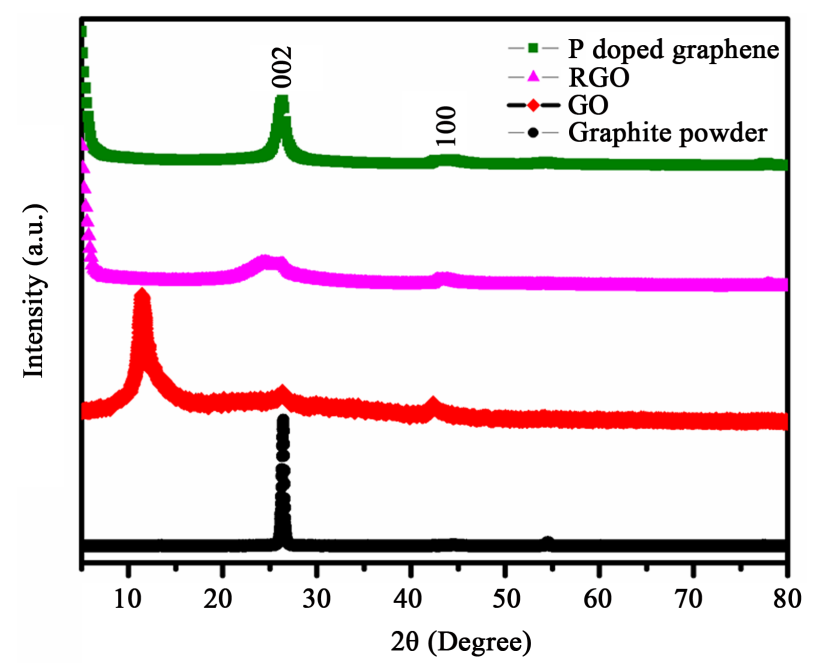

Figure 2. X-ray diffraction patterns of the phosphorous doped multilayered graphene material.

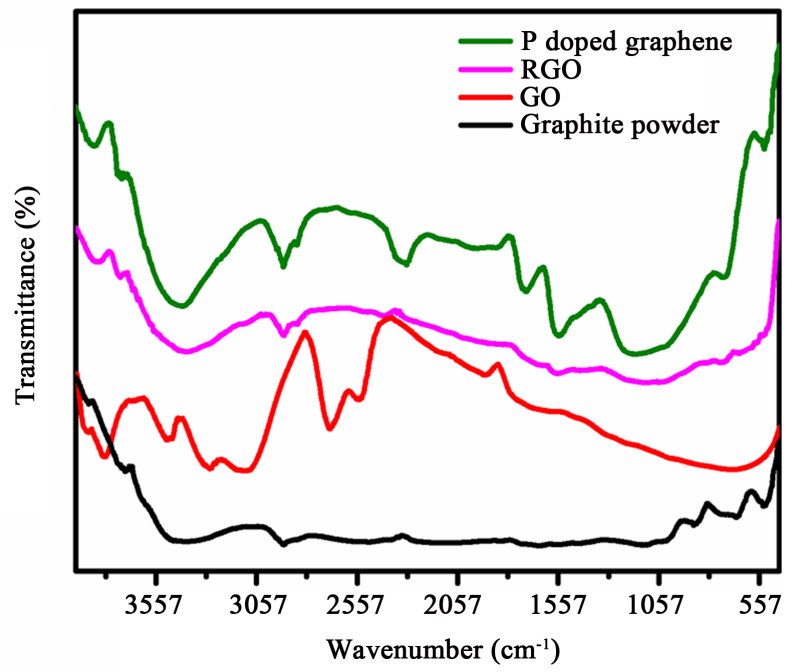

Figure 3. FT-IR spectrum of the phosphorous doped multilayered graphene material.

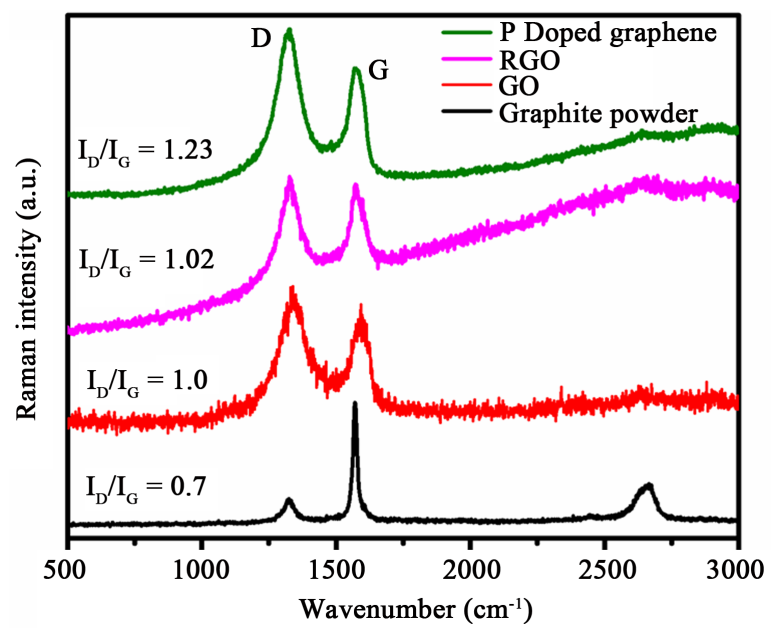

Figure 4. Raman spectrum of the phosphorous doped multilayered graphene material. 
phene was significantly larger than that of RGO. These observations suggested that the systematic restacking of graphene nanosheets in P-doped multilayered graphene. Probably more defect sites were created by P-doping on graphene material. These results revealed that the reduced graphene has been functionalized with phosphorous and formed P-doped multi-layered graphene sheets [68] [69].

The P-doped multilayered graphene shows significantly higher BET surface area and high pore volume than RGO, GO and Graphite powder, thus signifying the important role for the coexistence of phosphoric acid in the synthesis in increasing the surface area and porosity [70] (see Figure 5 and Table 1). The typical HRSEM images of the heteroatom (P) doped multilayered graphene can be seen in Figure 6. As shown in Figure 6(a) and Figure 6(b) these images confirmed that this material sustain the multilayers of graphene, and also surface becomes thin and transparent produced after heteroatom (P) substitution. The magnified HRSEM image shown in Figure 6(c) and Figure 6(d) it can be confirmed that a graphene prepared was with multilayers (see Figure 6). Furthermore detailed morphological structures of P-doped multilayered graphene were obtained by HRTEM and this shows the wavy and transparent layers of graphene (see Figure 7(a)) and also nanopores become visible on the surface of P-doped multilayered graphene (see Figure 7(b)).

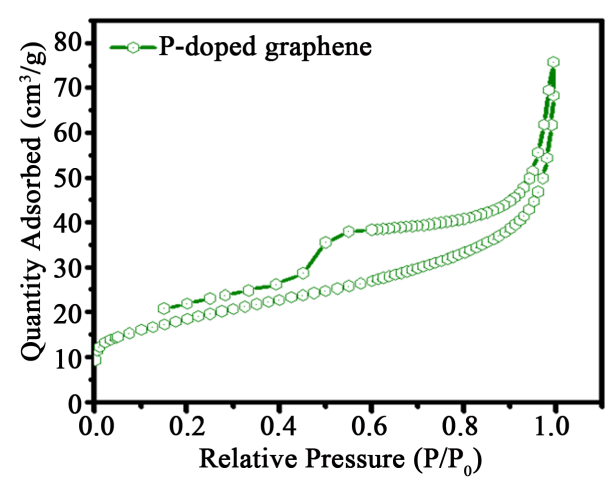

(a)

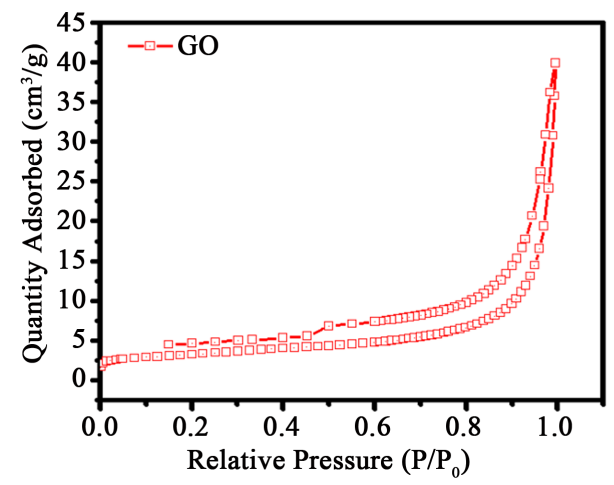

(c)

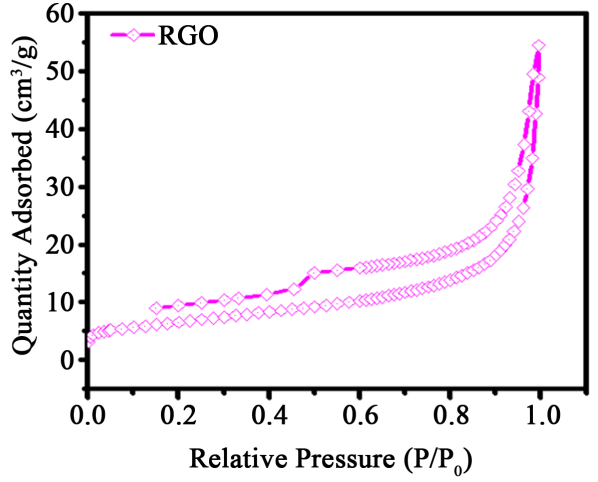

(b)

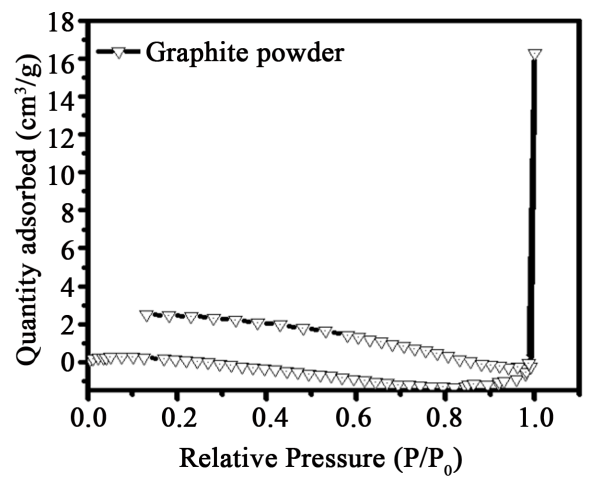

(d)

Figure 5. BET-Nitrogen adsorption/desorption isotherm of the phosphorous doped multilayered graphene material.

Table 1. BET- $\mathrm{N}_{2}$ sorption isotherm results and also the hydrogen adsorption/desorption results are summarized.

\begin{tabular}{cccccccc}
\hline S. No & Samples Name & $\begin{array}{c}\text { Surface } \\
\text { Area }\left(\mathrm{m}^{2} / \mathrm{g}\right)\end{array}$ & $\begin{array}{c}\text { External } \\
\text { Surface } \\
\text { Area }\left(\mathrm{m}^{2} / \mathrm{g}\right)\end{array}$ & $\begin{array}{c}\text { Micropore } \\
\text { Area }\left(\mathrm{m}^{2} / \mathrm{g}\right)\end{array}$ & $\begin{array}{c}\text { Total Pore } \\
\text { Volume }\left(\mathrm{cm}^{3} / \mathrm{g}\right)\end{array}$ & $\begin{array}{c}\text { Micropore } \\
\text { volume }\left(\mathrm{cm}^{3} / \mathrm{g}\right)\end{array}$ & $\begin{array}{c}\mathrm{H}_{2} \text { Adsorption } \\
\text { Capacity at } 298 \mathrm{~K} \\
\text { and } 100 \text { bar }(\mathrm{et} \%)\end{array}$ \\
\hline 1. & P-Doped Graphene & 75 & 64.10 & 10.5 & 0.117 & 0.0044 & 2.2 \\
2. & RGO & 24 & 20.8 & 2.45 & 0.093 & 0.0010 & 0.28 \\
3. & GO & 11 & 8.52 & 2.79 & 0.061 & 0.0013 & 0.20 \\
4. & Graphite & 0.60 & -0.76 & 1.45 & 0.011 & 0.0007 & 0.14 \\
\hline
\end{tabular}




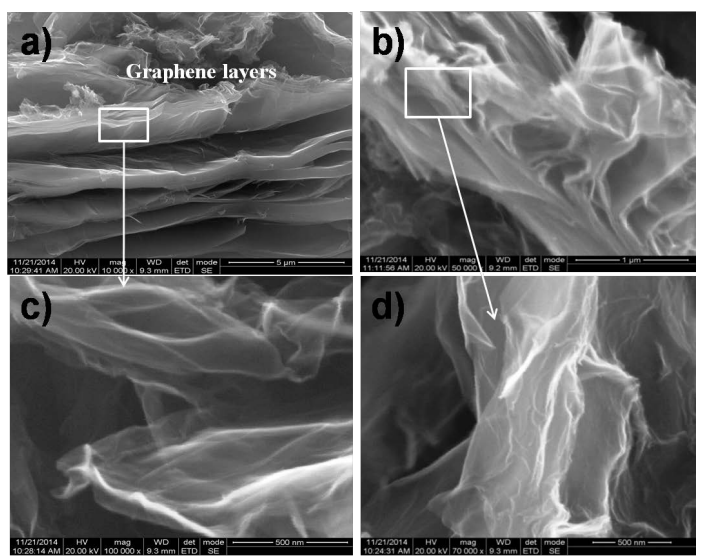

Figure 6. High resolution scanning electron microscopy (HRSEM) images of the phosphorous doped multilayered graphene material.

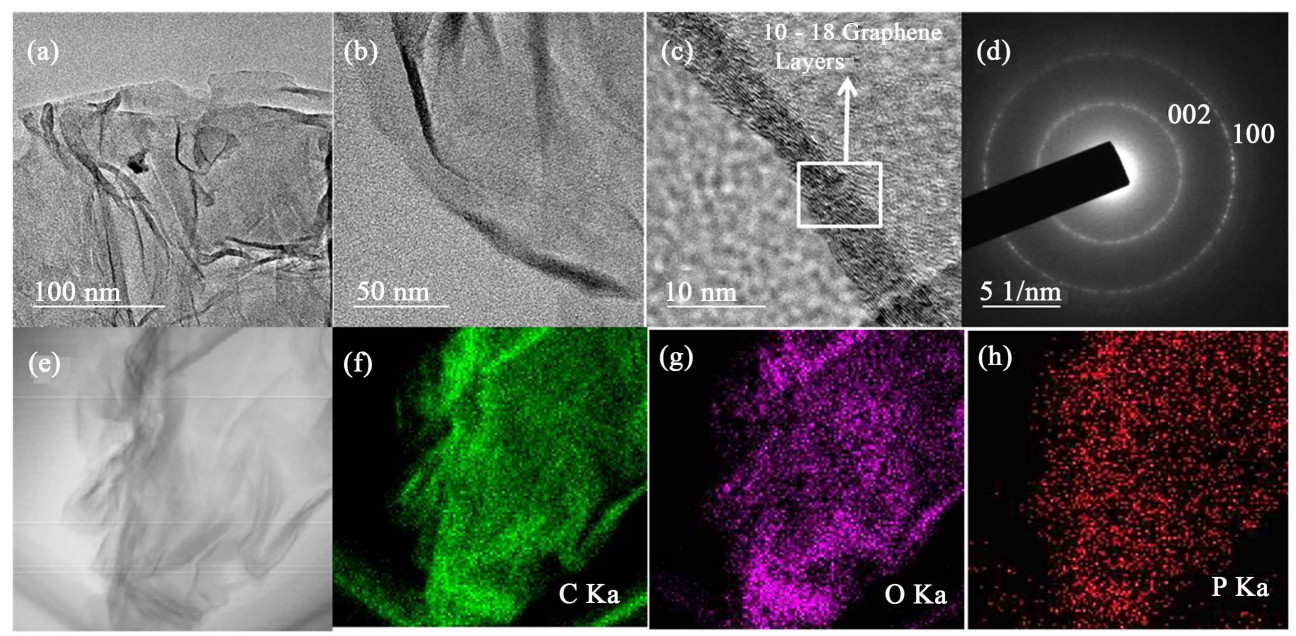

Figure 7. (a) (b) (c) HRTEM images elemental and (d) SAED pattern (e) STEM image (f) (g) (h) elemental mapping images of the phosphorous doped multilayered graphene material.

In addition the elemental mapping images confirmed the heteroatom (P) doping of the graphene (see Figures $7(f)-(h))$. X-ray photoelectron spectra (XPS) were obtained to investigate the surface species of graphene. These studies confirm that phosphorus is incorporated in the graphene material (see Figure 8). The hydrogen adsorption isotherms of the prepared graphene materials shows the hydrogen sorption capacity of $\sim 2.2 \mathrm{wt} \%$ at $298 \mathrm{~K}$ and 100 bar is shown in Figure 9.

Heteroatom doping, high surface areas are favorable for promoting hydrogen sorption [47] [51] [70] (see Table 1). The phosphorous-doped graphene material shows enhanced hydrogen sorption capacity compared to their counterpart namely reduced graphitic oxide materials (without $\mathrm{P}$ ). The enhancement of hydrogen sorption should be attributed to the spillover of hydrogen from the phosphorous doped graphene layers to the receptors, and also the surface area differences [71]. It is conceivable that the greater part of the heteroatom (P) may be segregating to the surface [71] [72]. Furthermore, another possible reason is that $\mathrm{P}$ is larger than $\mathrm{N}, \mathrm{P}$-doping causes more structural distortion. By transforming the $\mathrm{sp}_{2}$ hybridized carbon into the $\mathrm{sp}_{3}$ state, phosphorous can form a pyramidal like bonding configuration with three carbon atoms. In such a configuration, phosphorous overhangs from the graphene plane by $1.33 \%$ accompanied with $24.6 \%$ increase in the P-C bond length with respect to the $\mathrm{C}-\mathrm{C}$ bond length of pristine graphene which providing more space for hydrogen storage. While considering these viewpoints, heteroatoms such as $\mathrm{N}, \mathrm{P}, \mathrm{S}$ and B appear to be promising activators in heteroatom containing carbon materials for hydrogen storage application [73] [74]. Moreover the heteroatom substitution in carbon lattice is known to generate various functional groups and these functional groups are potential active 


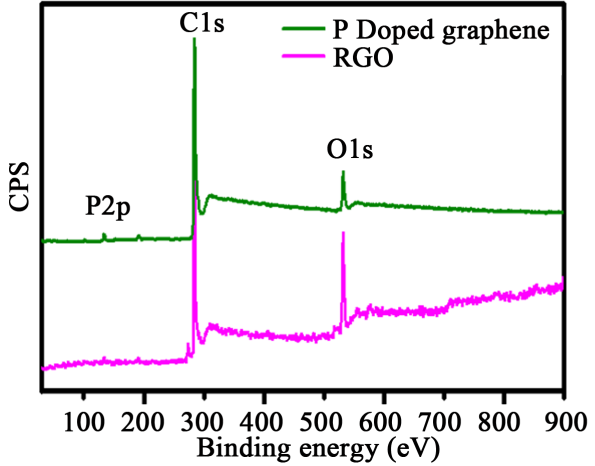

(a)

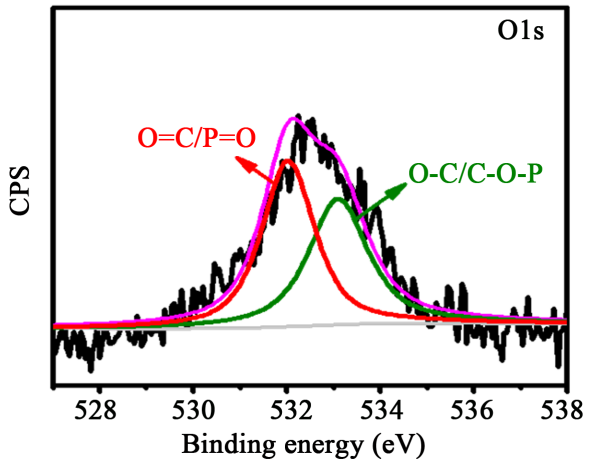

(c)

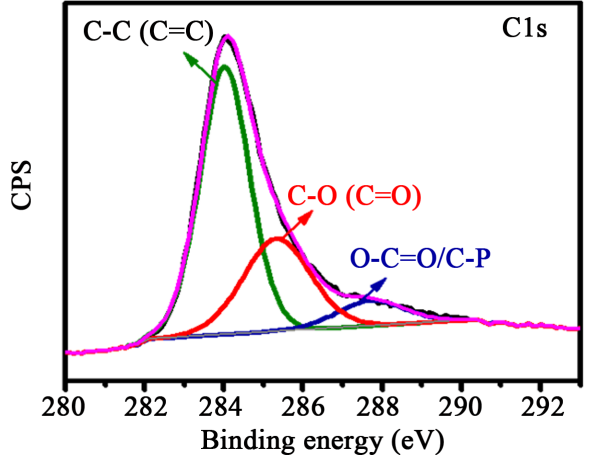

(b)

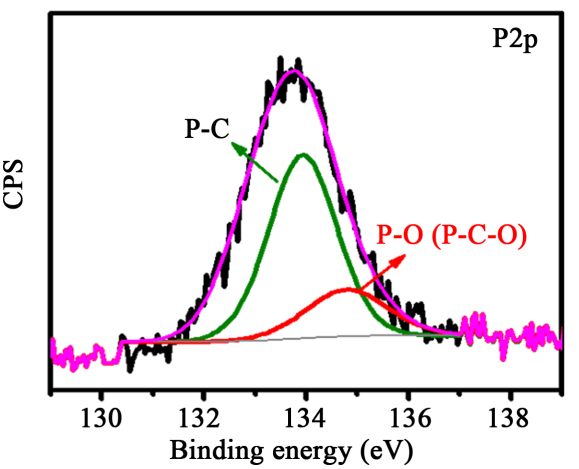

(d)

Figure 8. (a) X-ray photoelectron spectroscopy (XPS) survey spectrum of RGO and phosphorous doped multilayered graphene (b) C1s (c) O1s and (d) P2p convolution spectrum of the graphene material.

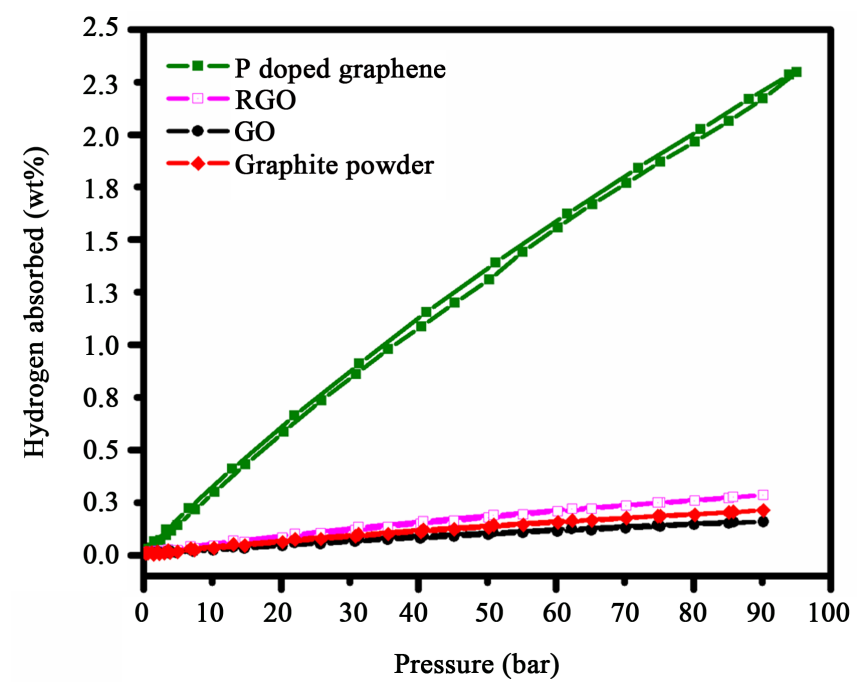

Figure 9. Hydrogen adsorption/desorption isotherms of the phosphorous doped multilayered graphene, RGO, GO and graphite.

sites for the dissociation of hydrogen molecule in combination with an adjacent carbon atom since the bond elongation in hydrogen molecule could be effected. In addition, it is possible that the population of charge density in the antibonding levels of hydrogen molecule could be achieved by the heteroatom adsorption sites which can also facilitate the dissociation of hydrogen molecule. 


\section{Conclusion}

In summary, a facile route for the preparation of phosphorous containing graphene material has been proposed. The heteroatom substituted graphene material showed a hydrogen sorption capacity of $\sim 2.2 \mathrm{wt} \%$ at $298 \mathrm{~K}$ and 100 bar. The proposed synthesis can be an alternative method for P-doped graphene with developed specific phosphorous species for hydrogen adsorption as well as green energy exploitation and sustainable environmental preservation.

\section{Acknowledgements}

The authors wish to record their grateful thanks to the Department of Science and Technology (DST) for setting up National Centre for Catalysis Research and Ministry New and Renewable Energy (MNRE) of the Government of India for supporting the hydrogen storage activity of this centre.

\section{References}

[1] Liu, C., Fan, Y.Y., Liu, M., Cong, H.T., Cheng, H.M. and Dresselhaus, M.S. (1999) Hydrogen Storage in SingleWalled Carbon Nanotubes at Room Temperature. Science, 286, 1127-1129. http://dx.doi.org/10.1126/science.286.5442.1127

[2] Jena, P. (2011) Materials for Hydrogen Storage: Past, Present, and Future. The Journal of Physical Chemistry Letters, 2, 206-211. http://dx.doi.org/10.1021/jz1015372

[3] Bonaccorso, F., Colombo, L., Yu, G., Stoller, M., Tozzini, V., Ferrari, A.C., Ruoff, R.S. and Pellegrini, V. (2015) Graphene, Related Two-Dimensional Crystals, and Hybrid Systems for Energy Conversion and Storage. Science, 347. http://dx.doi.org/10.1126/science.1246501

[4] Kowalczyk, P., Holyst, R., Terrones, M. and Terrones, H. (2007) Hydrogen Storage in Nanoporous Carbon Materials: Myth and Facts. Physical Chemistry Chemical Physics, 9, 1786-1792. http://dx.doi.org/10.1039/b618747a

[5] Graetz, J. (2009) New Approaches to Hydrogen Storage. Chemical Society Reviews, 38, 73-82. http://dx.doi.org/10.1039/B718842K

[6] Ströbel, R., Garche, J., Moseley, P.T., Jörissen, L. and Wolf, G. (2006) Hydrogen Storage by Carbon Materials. Journal of Power Sources, 159, 781-801. http://dx.doi.org/10.1016/j.jpowsour.2006.03.047

[7] Chambers, A., Park, C., Baker, R.T.K. and Rodriguez, N.M. (1998) Hydrogen Storage in Graphite Nanofibers. The Journal of Physical Chemistry B, 102, 4253-4256. http://pubs.acs.org/doi/abs/10.1021/jp980114l

[8] Li, C. and Shi, G. (2012) Three-Dimensional Graphene Architectures. Nanoscale, 4, 5549-5563. http://dx.doi.org/10.1039/c2nr31467c

[9] Rao, C.N.R., Sood, A.K., Subrahmanyam, K.S. and Govindaraj, A. (2009) Graphene: The New Two-Dimensional Nanomaterial. Angewandte Chemie International Edition, 48, 7752-7777. http://dx.doi.org/10.1002/anie.200901678

[10] Georgakilas, V., Otyepka, M., Bourlinos, A.B., Chandra, V., Kim, N., Kemp, K.C., Hobza, P., Zboril, R. and Kim, K.S. (2012) Functionalization of Graphene: Covalent and Non-Covalent Approaches, Derivatives and Applications. Chemical Reviews, 112, 6156-6214. http://dx.doi.org/10.1021/cr3000412

[11] Zhu, Y., James, D.K. and Tour, J.M. (2012) New Routes to Graphene, Graphene Oxide and Their Related Applications. Advanced Materials, 24, 4924-4955. http://dx.doi.org/10.1002/adma.201202321

[12] Novoselov, K.S., Geim, A.K., Morozov, S.V., Jiang, D., Zhang, Y., Dubonos, S.Y., Grigorieva, I.V. and Firsov, A.A. (2014) Electric Field Effect in Atomically Thin Carbon Films. Science, 306, 666-669. http://dx.doi.org/10.1126/science.1102896

[13] Jiang, H. (2011) Chemical Preparation of Graphene-Based Nanomaterials and Their Applications in Chemical and Biological Sensors. Small, 7, 2413-2427. http://onlinelibrary.wiley.com/doi/10.1002/smll.201002352/abstract

[14] Geim, A.K. and Novoselov, K.S. (2007) The Rise of Graphene. Nature Materials, 6, 183-191. http://dx.doi.org/10.1038/nmat1849

[15] Tung, V.C., Allen, M.J., Yang, Y. and Kaner, R.B. (2009) High-Throughput Solution Processing of Large-Scale Graphene. Nature Nanotechnology, 4, 25-29. http://dx.doi.org/10.1038/nnano.2008.329

[16] Li, D., Muller, M.B., Gilje, S., Kaner, R.B. and Wallace, G.G. (2008) Processable Aqueous Dispersions of Graphene Nanosheets. Nature Nanotechnology, 3, 101-105. http://dx.doi.org/10.1038/nnano.2007.451

[17] Wei, Z., Wang, D., Kim, S., Kim, S.Y., Hu, Y., Yakes, M.K., Laracuente, A.R., Dai, Z., Marder, S.R., Berger, C., King, 
W.P., De Heer, W.R., Sheehan, P.E. and Riedo, E. (2010) Nanoscale Tunable Reduction of Graphene Oxide for Graphene Electronics. Science, 328, 1373-1376. http://dx.doi.org/10.1126/science.1188119

[18] Huang, X., Qi, X., Boey, F. and Zhang, H. (2012) Graphene-Based Composites. Chemical Society Reviews, 41, 666686. http://dx.doi.org/10.1039/C1CS15078B

[19] Huang, C., Li, C. and Shi, G. (2012) Graphene Based Catalysts. Energy \& Environmental Science, 5, 8848-8868. http://dx.doi.org/10.1039/c2ee22238h

[20] Huang, X., Yin, Z., Wu, S., Qi, X., He, Q., Zhang, Q., Yan, Q., Boey, F. and Zhang, H. (2011) Graphene-Based Materials: Synthesis, Characterization, Properties, and Applications. Small, 7, 1876-1902. http://dx.doi.org/10.1002/smll.201002009

[21] Chen, D., Tang, L. and Li, J. (2010) Graphene-Based Materials in Electrochemistry. Chemical Society Reviews, 39, 3157-3180. http://dx.doi.org/10.1039/b923596e

[22] Jiang, H., Zhu, Y., Su, Y., Yao, Y., Liu, Y., Yang, X. and Li, C. (2015) Highly Dual-Doped Multilayer Nanoporous Graphene: Efficient Metal-Free Electrocatalysts for the Hydrogen Evolution Reaction. Journal of Materials Chemistry A, 3, 12642-12645. http://dx.doi.org/10.1039/C5TA02792F

[23] Berger, C., Song, Z., Li, T., Li, X., Ogbazghi, A.Y., Feng, R., Dai, Z., Marchenkov, A.N., Conrad, E.H., First, P.N. and De Heer, W.A. (2004) Ultrathin Epitaxial Graphite: 2D Electron Gas Properties and a Route toward Graphene-Based Nanoelectronics. The Journal of Physical Chemistry B, 108, 19912-19916. http://dx.doi.org/10.1021/jp040650f

[24] Baitimbetova, B. and Vermenichev, B. (2015) New Method for Producing Graphene by Magnetron Discharge in an Atmosphere of Aromatic Hydrocarbons. Graphene, 4, 38-44. http://dx.doi.org/10.4236/graphene.2015.42004

[25] Kim, Y.A., Hayashi, T., Kim, J.H. and Endo, M. (2013) Important Roles of Graphene Edges in Carbon-Based Energy Storage Devices. Journal of Energy Chemistry, 22, 183-194. http://dx.doi.org/10.1016/S2095-4956(13)60024-8

[26] Stoller, M.D., Park, S., Zhu, Y., An, J. and Ruoff, R.S. (2008) Graphene-Based Ultracapacitors. Nano Letters, 8, 34983502. http://dx.doi.org/10.1021/nl802558y

[27] Stankovich, S., Dikin, D.A., Dommett, G.H.B., Kohlhaas, K.M., Zimney, E.J., Stach, E.A., Piner, R.D., Nguyen, S.T. and Ruoff, R.S. (2006) Graphene-Based Composite Materials. Nature, 442, 282-286. http://dx.doi.org/10.1038/nature04969

[28] Bolotin, K.I., Sikes, K.J., Jiang, Z., Klima, M., Fudenberg, G., Hone, J., Kim, P. and Stormer, H.L. (2008) Ultrahigh Electron Mobility in Suspended Graphene. Solid State Communications, 146, 351-355. http://dx.doi.org/10.1016/j.ssc.2008.02.024

[29] Di, C.A., Wei, D., Yu, G., Liu, Y., Guo, Y. and Zhu, D. (2008) Patterned Graphene as Source/Drain Electrodes for Bottom-Contact Organic Field-Effect Transistors. Advanced Materials, 20, 3289-3293. http://dx.doi.org/10.1002/adma.200800150

[30] Wu, J., Pisula, W. and Müllen, K. (2007) Graphenes as Potential Material for Electronics. Chemical Reviews, 107, 718747. http://dx.doi.org/10.1021/cr068010r

[31] Geng, D., Chen, Y., Chen, Y., Li, Y., Li, R., Sun, X., Ye, S. and Knights, S. (2011) High Oxygen-Reduction Activity and Durability of Nitrogen-Doped Graphene. Energy \& Environmental Science, 4, 760-764. http://dx.doi.org/10.1039/c0ee00326c

[32] Nair, R.R., Blake, P., Grigorenko, A.N., Novoselov, K.S., Booth, T.J., Stauber, T., Peres, N.M.R. and Geim, A.K. (2008) Fine Structure Constant Defines Visual Transparency of Graphene. Science, 320, 1308. http://dx.doi.org/10.1126/science.1156965

[33] Jiang, H., Zhu, Y., Feng, Q., Su, Y., Yang, X. and Li, C. (2014) Nitrogen and Phosphorus Dual-Doped Hierarchical Porous Carbon Foams as Efficient Metal-Free Electrocatalysts for Oxygen Reduction Reactions. Chemistry-A European Journal, 20, 3106-3112. http://dx.doi.org/10.1002/chem.201304561

[34] Chen, L., Xia, K., Huang, L., Li, L., Pei, L. and Fei, S. (2013) Facile Synthesis and Hydrogen Storage Application of Nitrogen-Doped Carbon Nanotubes with Bamboo-Like Structure. International Journal of Hydrogen Energy, 38, 32973303. http://dx.doi.org/10.1016/j.ijhydene.2013.01.055

[35] Umegaki, T., Yan, J.M., Zhang, X.B., Shioyama, H., Kuriyama, N. and Xu, Q. (2009) Boron- and Nitrogen-Based Chemical Hydrogen Storage Materials. International Journal of Hydrogen Energy, 34, 2303-2311. http://dx.doi.org/10.1016/j.ijhydene.2009.01.002

[36] Sankaran, M. and Viswanathan, B. (2006) The Role of Heteroatoms in Carbon Nanotubes for Hydrogen Storage. Carbon, 44, 2816-2821. http://dx.doi.org/10.1016/j.carbon.2006.03.025

[37] Sankaran, M. and Viswanathan, B. (2007) Hydrogen Storage in Boron Substituted Carbon Nanotubes. Carbon, 45, 1628-1635. http://dx.doi.org/10.1016/j.carbon.2007.04.011

[38] Sankaran, M., Viswanathan, B. and Murthy, S.S. (2008) Boron Substituted Carbon Nanotubes—How Appropriate Are 
They for Hydrogen Storage? International Journal of Hydrogen Energy, 33, 393-403. http://dx.doi.org/10.1016/j.ijhydene.2007.07.042

[39] Zion, E., Haran, A., Butenko, A., Wolfson, L., Kaganovskii, Y., Havdala, T., Sharoni, A., Naveh, D., Richter, V., Kaveh, M., et al. (2015) Localization of Charge Carriers in Monolayer Graphene Gradually Disordered by Ion Irradiation. Graphene, 4, 45-53. http://dx.doi.org/10.4236/graphene.2015.43005

[40] Viswanathan, B., Murugesan, S., Ariharan, A. and Lakhi, K.S. (2013) Hetero Atom Substituted Carbon-Potential Hydrogen Storage Materials. Advanced Porous Materials, 1, 122-128. http://dx.doi.org/10.1166/apm.2013.1008

[41] Jin, Z., Sun, Z., Simpson, L.J., O’Neill, K.I., Parilla, P.A., Li, Y., Stadie, N.P., Ahn, C.C., Kittrell, C. and Tour, J.M. (2010) Solution-Phase Synthesis of Heteroatom-Substituted Carbon Scaffolds for Hydrogen Storage. Journal of the American Chemical Society, 132, 15246-15255. http://dx.doi.org/10.1021/ja105428d

[42] Wang, X., Sun, G., Routh, P., Kim, D.H., Huang, W. and Chen, P. (2010) Heteroatom-Doped Graphene Materials: Syntheses, Properties and Applications. Chemical Society Reviews, 43, 7067-7098. http://dx.doi.org/10.1039/C4CS00141A

[43] Li, N., Wang, Z., Zhao, K., Shi, Z., Gu, Z. and Xu, S. (2010) Large Scale Synthesis of N-Doped Multi-Layered Graphene Sheets by Simple Arc-Discharge Method. Carbon, 48, 255-259. http://dx.doi.org/10.1016/j.carbon.2009.09.013

[44] Li, R., Wei, Z. and Gou, X. (2015) Nitrogen and Phosphorus Dual-Doped Graphene/Carbon Nanosheets as Bifunctional Electrocatalysts for Oxygen Reduction and Evolution. ACS Catalysis, 5, 4133-4142. http://dx.doi.org/10.1021/acscatal.5b00601

[45] Gadipelli, S. and Guo, Z.X. (2015) Graphene-Based Materials: Synthesis and Gas Sorption, Storage and Separation. Progress in Materials Science, 69, 1-60. http://dx.doi.org/10.1016/j.pmatsci.2014.10.004

[46] Zhu, Y.P., Liu, Y., Liu, Y.P., Ren, T.Z., Chen, T. and Yuan, Z.Y. (2015) Direct Synthesis of Phosphorus-Doped Mesoporous Carbon Materials for Efficient Electrocatalytic Oxygen Reduction. ChemCatChem, 7, 2903-2909. http://dx.doi.org/10.1002/cctc.201500148

[47] Tozzini, V. and Pellegrini, V. (2013) Prospects for Hydrogen Storage in Graphene. Physical Chemistry Chemical Physics, 15, 80-89. http://dx.doi.org/10.1039/C2CP42538F

[48] Zhu, Y.P., Liu, Y., Liu, Y.P., Ren, T.Z., Du, G.H., Chen, T. and Yuan, Z.Y. (2015) Heteroatom-Doped Hierarchical Porous Carbons as High-Performance Metal-Free Oxygen Reduction Electrocatalysts. Journal of Materials Chemistry A, 3, 11725-11729. http://dx.doi.org/10.1039/C5TA01611H

[49] Sheng, Z.H., Gao, H.L., Bao, W.J., Wang, F.B. and Xia, X.H. (2012) Synthesis of Boron Doped Graphene for Oxygen Reduction Reaction in Fuel Cells. Journal of Materials Chemistry, 22, 390-395. http://dx.doi.org/10.1039/C1JM14694G

[50] Razmjooei, F., Singh, K.P., Song, M.Y. and Yu, J.S. (2014) Enhanced Electrocatalytic Activity Due to Additional Phosphorous Doping in Nitrogen and Sulfur-Doped Graphene: A Comprehensive Study. Carbon, 78, 257-267. http://dx.doi.org/10.1016/j.carbon.2014.07.002

[51] Wen, Y., Wang, B., Huang, C., Wang, L. and Hulicova-Jurcakova, D. (2015) Synthesis of Phosphorus-Doped Graphene and Its Wide Potential Window in Aqueous Supercapacitors. Chemistry-A European Journal, 21, 80-85. http://dx.doi.org/10.1002/chem.201404779

[52] Poh, H.L., Sofer, Z., Nováček, M. and Pumera, M. (2014) Concurrent Phosphorus Doping and Reduction of Graphene Oxide. Chemistry - A European Journal, 20, 4284-4291. http://dx.doi.org/10.1002/chem.201304217

[53] Long, D., Li, W., Ling, L., Miyawaki, J., Mochida, I. and Yoon, S.H. (2010) Preparation of Nitrogen-Doped Graphene Sheets by a Combined Chemical and Hydrothermal Reduction of Graphene Oxide. Langmuir, 26, 16096-16102. http://dx.doi.org/10.1021/la102425a

[54] Choi, C.H., Park, S.H. and Woo, S.I. (2012) Phosphorus-Nitrogen Dual Doped Carbon as an Effective Catalyst for Oxygen Reduction Reaction in Acidic Media: Effects of the Amount of P-Doping on the Physical and Electrochemical Properties of Carbon. Journal of Materials Chemistry, 22, 12107-12115. http://dx.doi.org/10.1039/c2jm31079a

[55] Parambhath, V.B., Nagar, R. and Ramaprabhu, S. (2012) Effect of Nitrogen Doping on Hydrogen Storage Capacity of Palladium Decorated Graphene. Langmuir, 28, 7826-7833. http://dx.doi.org/10.1021/la301232r

[56] Han, J.C., Liu, A.P., Zhu, J.Q., Tan, M.L. and Wu, H.P. (2007) Effect of Phosphorus Content on Structural Properties of Phosphorus Incorporated Tetrahedral Amorphous Carbon Films. Applied Physics A, 88, 341-345. http://dx.doi.org/10.1007/s00339-007-3938-4

[57] Chaudhari, N.K., Song, M.Y. and Yu, J.S. (2014) Heteroatom-Doped Highly Porous Carbon from Human Urine. Scientific Reports, 4, 5221. http://dx.doi.org/10.1038/srep05221

[58] Li, R., Wei, Z., Gou, X. and Xu, W. (2013) Phosphorus-Doped Graphene Nanosheets as Efficient Metal-Free Oxygen Reduction Electrocatalysts. RSC Advances, 3, 9978-9984. http://dx.doi.org/10.1039/c3ra41079j 
[59] Puziy, A.M., Poddubnaya, O.I., Martinez-Alonso, A., Suárez-García, F. and Tascón, J.M. (2002) Synthetic Carbons Activated with Phosphoric Acid: I. Surface Chemistry and Ion Binding Properties. Carbon, 40, 1493-1505 http://dx.doi.org/10.1016/S0008-6223(01)00317-7

[60] Claeyssens, F., Fuge, G.M., Allan, N.L., May, P.W. and Ashfold, M.N.R. (2004) Phosphorus Carbides: Theory and Experiment. Dalton Transactions, 19, 3085-3092. http://dx.doi.org/10.1039/b402740j

[61] Claypool, S., Kalaga, K., Reddy, A.L.M., Currano, L.J., Dubey, M. and Ajayan, P.M. (2013) Graphene Based Energetic Materials: A Case Study. Graphene, 1, 11-15. http://dx.doi.org/10.1166/graph.2013.1003

[62] Seredych, M., Wu, C.T., Brender, P., Ania, C.O., Vix-Guterl, C. and Bandosz, T.J. (2012) Role of Phosphorus in Carbon Matrix in Desulfurization of Diesel Fuel Using Adsorption Process. Fuel, 92, 318-326. http://dx.doi.org/10.1016/j.fuel.2011.08.007

[63] Karthika, P., Rajalakshmi, N. and Dhathathreyan, K.S. (2013) Phosphorus-Doped Exfoliated Graphene for Supercapacitor Electrodes. Journal of Nanoscience and Nanotechnology, 13, 1746-1751. http://dx.doi.org/10.1166/jnn.2013.7112

[64] Puziy, A.M., Poddubnaya, O.I. and Ziatdinov, A.M. (2006) On the Chemical Structure of Phosphorus Compounds in Phosphoric Acid-Activated Carbon. Applied Surface Science, 252, 8036-8038. http://dx.doi.org/10.1016/j.apsusc.2005.10.044

[65] Wang, C., Zhou, Y., Sun, L., Wan, P., Zhang, X. and Qiu, J. (2013) Sustainable Synthesis of Phosphorus- and Nitrogen-Co-Doped Porous Carbons with Tunable Surface Properties for Supercapacitors. Journal of Power Sources, 239, 81-88. http://dx.doi.org/10.1016/j.jpowsour.2013.03.126

[66] Hummers, W.S. and Offeman, R.E. (1958) Preparation of Graphitic Oxide. Journal of the American Chemical Society, 80, 1339. http://dx.doi.org/10.1021/ja01539a017

[67] Malard, L.M., Pimenta, M.A., Dresselhaus, G. and Dresselhaus, M.S. (2009) Raman Spectroscopy in Graphene. Physics Reports, 473, 51-87. http://dx.doi.org/10.1016/j.physrep.2009.02.003

[68] Wen, Z., Wang, X., Mao, S., Bo, Z., Kim, H., Cui, S., Lu, G., Feng, X. and Chen, J. (2012) Crumpled Nitrogen-Doped Graphene Nanosheets with Ultrahigh Pore Volume for High-Performance Supercapacitor. Advanced Materials, 24, 5610-5616. http://dx.doi.org/10.1002/adma.201201920

[69] Graf, D., Molitor, F., Ensslin, K., Stampfer, C., Jungen, A., Hierold, C. and Wirtz, L. (2007) Spatially Resolved Raman Spectroscopy of Single- and Few-Layer Graphene. Nano Letters, 7, 238-242. http://dx.doi.org/10.1021/nl061702a

[70] Jin, J., Fu, L., Yang, H. and Ouyang, J. (2015) Carbon Hybridized Halloysite Nanotubes for High-Performance Hydrogen Storage Capacities. Scientific Reports, 5, 12429-12439. http://dx.doi.org/10.1038/srep12429

[71] Ariharan, A., Viswanathan, B. and Nandhakumar, V. (2016) Hydrogen Storage on Boron Substituted Carbon Materials. International Journal of Hydrogen Energy, 41, 3527-3536. http://dx.doi.org/10.1016/j.ijhydene.2015.12.169

[72] Zhang, J. and Dai, L. (2015) Heteroatom-Doped Graphitic Carbon Catalysts for Efficient Electrocatalysis of Oxygen Reduction Reaction. ACS Catalysis, 5, 7244-7253. http://dx.doi.org/10.1021/acscatal.5b01563

[73] Lee, Y.J. and Radovic, L.R. (2003) Oxidation Inhibition Effects of Phosphorus and Boron in Different Carbon Fabrics. Carbon, 41, 1987-1997. http://dx.doi.org/10.1016/s0008-6223(03)00199-4

[74] Ariharan, A., Viswanathan, B. and Nandhakumar, V. (2015) Hydrogen Sorption in Phosphorous Substituted Carbon Material. Indian Journal of Chemistry Section A, 54, 1423-1433. http://nopr.niscair.res.in/handle/123456789/33505 